\title{
Effect of Carbon and Organoclay Fillers on Partial Discharge and Corrosion Properties of Polyurethane Base Composite Coated on Aluminum Alloy
}

\author{
Bambang Soegijono, ${ }^{\mathrm{a},}{ }^{\dagger}$ M. Yudi Masduky Solihin, ${ }^{\mathrm{b}}$ Ova Kurniawan, ${ }^{\mathrm{a}}$ Emil Budianto ${ }^{\mathrm{c}}$ \\ ${ }^{a}$ Department of Physics, Universitas Indonesia, Depok 16424, Indonesia \\ ${ }^{\mathrm{b}}$ Department of Industrial Engineering, Universitas Pancasila, Jakarta 12640, Indonesia \\ ' Department of Chemistry, Universitas Indonesia, Depok 16424, Indonesia \\ $\dagger$ Corresponding author: naufal@ui.ac.id
}

Received: 20 July, 2020; Accepted: 2 December, 2020; Published: 10 December, 2020

The corrosion and partial discharge of the aluminum alloy conductor, which may occur during operation, can be reduced by coating the aluminum alloy with other materials. This research investigates the corrosion and partial discharge of the aluminum alloy conductor coated with polyurethane/carbon/organoclay (PCClay) composite materials. Polyurethane as a matrix, and carbon and organoclay as a filler were used as composites. Potentiodynamic and partial charge tests were conducted to measure the corrosion rate and partial discharge behavior versus volt-
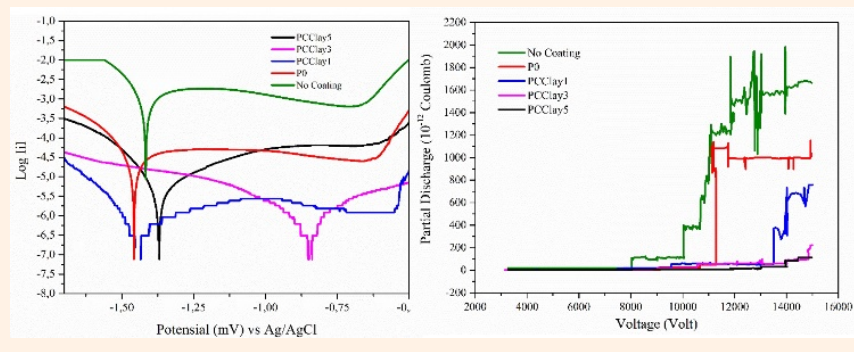
age. The results showed that increasing the filler content may lead to agglomeration, decrease corrosion resistance, and decrease partial discharge. The voltage, where the initial partial discharge occurs, increases as the filler content increases.

Keywords Polyurethane; Composite; Corrosion rate; Partial discharge

\section{INTRODUCTION}

In modern times, electrical utilities provide more reliable power and minimal power interruption to transmit electricity from the generator power plant. The transmission line made from the aluminum alloy conductor is used as the primary material [1]. The aluminum alloy conductor is the primary conductive material for a high-voltage overhead electrical transmission line. In an outdoor environment, the aluminum alloy conductor's physical characteristics deteriorate and are prone to corrosion due to their complex environment [2-4]. Certain factors, such as industrial pollution or marine salts in the air, may cause severe corrosion [5]. On the other hand, attention must be paid to partial discharge during the operation due to corona losses. Partial discharge in high voltage equipment generally indicates a defect and weakness in the insulation of high-voltage systems [6]. One of the methods used to reduce corrosion and degradation on the conductor is by coating the conductor to prevent direct contact between the conductor and the atmosphere/air. It is mandatory that the coating material has features to prevent corrosion.

More attention has been paid in the last decade to polyurethane containing additive coating [7]. Polyurethane has a wide variety of forms. They are an advantageous commercial polymer material used both in industry and in daily life. Based on previous works [8, 9], polyurethane/clay composites have useful properties for multifunctional applications including coating materials. The clay in polyurethane improves the flame retardant and the mechanical properties of the composites [10]. The addition of carbon graphite improves the fire resistance of polyurethane foams but deteriorates the bending strength due to poor adhesion to the polyurethane matrix [11]. The polyurethane/carbon/organoclay composites have been studied as a coating that contributes to reducing corrosion [12]. Extensive studies have also been conducted on partial discharge, particularly on the insulator material. In the case of an epoxy resin insulator, it has been confirmed that the discharge resistance could be improved by adding a small amount of nano-inorganic filler [13-15]. A previous study reported that the thermal stability, dielec- 
tric, adhesion to the aluminum alloy, and water vapor permeability properties were affected by the carbon and organoclay as a filler [12].

As a continuation of the previous study, and to better understand partial discharge, the objective of this research is to report the partial discharge performance and corrosion resistance of polyurethane/carbon/organoclay composite material coated on aluminum alloys.

\section{EXPERIMENTAL}

The sample was all aluminum alloy conductors (AAAC) coated with polyurethane/carbon/organoclay composite materials. The aluminum alloy wire that was used as a conductor in the overhead power line was purchased commercially. The aluminum alloy contains $0.5 \% \mathrm{Si}, 0.7 \% \mathrm{Mg}, 0.5 \% \mathrm{Fe}$, $0.1 \% \mathrm{Cu}, 0.03 \% \mathrm{Mn}, 0.03 \% \mathrm{Cr}, 0.06 \% \mathrm{~B}$, and $1 \% \mathrm{Zn}$. For testing purposes, the aluminum alloy was melted and then molded. The substrate plate size was $2 ? 2 ? 0.5 \mathrm{~cm}$.

The polyurethane was also purchased commercially. The chemical composition of polyurethane is methylene diphenyl diisocyanate (MDI), and the MDI is based on polyisocyanate 4.4'-diphenylmethane, isobutyl acetate, and aromatic solved blend.

The carbon graphite powder with a 30 mesh $(0.23$ in or 95 $\mu \mathrm{m})$ was used as a filler material. The organoclay was obtained from the commercial production of Nanolin DK 8 (with particle size $1-100 \mu \mathrm{m}$ ).

The composite contains polyurethane as a matrix and carbon/organoclay as fillers. The polyurethane, carbon, and clay were mixed using a magnetic stirrer with a composition listed in Table 1. The stirring process was conducted for 120 min. with a speed of $500 \mathrm{rpm}$. The composites were coated onto the aluminum alloy substrate using the high-volume low-pressure (HVLP) method and dried at room temperature for $24 \mathrm{~h}$. The thickness of the composite was about $0.35 \mathrm{~mm}$, and it was measured using a digital micrometer. Figure 1 presents a sample of the aluminum alloys coated with polyurethane/carbon/organoclay composite material and the sample's cross-section. The image was obtained by using an optical microscope (Zeiss Axio Lab A, Carl Zeiss).

Four types of composites were prepared: 1) P0 (polyurethane without a filler), 2) PCClay1 (polyurethane filled with $1 \mathrm{wt} \%$ carbon and $1 \mathrm{wt} \%$ organoclay), 3) PCClay3 (polyurethane filled with $3 \mathrm{wt} \%$ carbon and $3 \mathrm{wt} \%$ organoclay),

Table 1: Composition of polyurethane/carbon/organoclay composites.

\begin{tabular}{lccc}
\hline \multirow{2}{*}{ Sample } & \multicolumn{3}{c}{ Composition (wt\%) } \\
\cline { 2 - 4 } & Polyurethane & Carbon & Organoclay \\
\hline P0 & 100 & 0 & 0 \\
PCClay1 & 98 & 1 & 1 \\
PCClay3 & 94 & 3 & 3 \\
PCClay5 & 90 & 5 & 5 \\
\hline
\end{tabular}
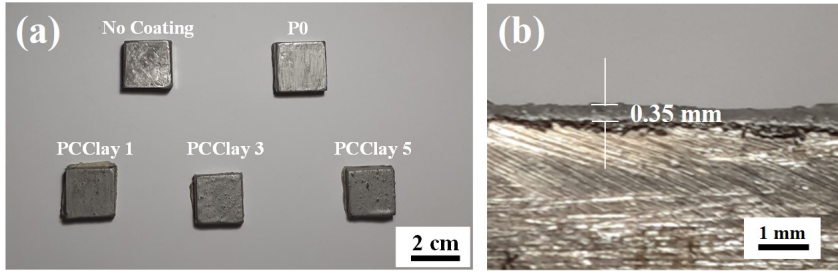

Figure 1: (a) Aluminum alloy conductor substrates that have been coated with composite materials. (b) A cross-section of one of the samples.

and 4) PCClay5 (polyurethane filled with $5 \mathrm{wt} \%$ carbon and $5 \mathrm{wt} \%$ organoclay). Table 1 shows the composition of the composite material.

The corrosion resistance measurement of the samples was conducted using the linear sweep voltammetry method using a potentiostat (DY2311, Digi-Ivy) to obtain a curve related to the potential and the current log. The anode and the cathode of the Tafel liner equation produced by the potentiostat were then calculated to obtain the polarization curve. Potentiodynamic measurements were carried out using a three-electrode system and glass containing $100 \mathrm{~mL}$ of a $3.5 \% \mathrm{NaCl}$ solution at room temperature.

The samples were prepared with an exposed surface area of $2 \mathrm{~cm} \times 2 \mathrm{~cm}$. A $10-\mathrm{mV} \mathrm{s}^{-1}$ scan rate between -2 and $+2 \mathrm{~V}$ was applied to obtain potentiodynamic curves. A silver chloride electrode $(\mathrm{Ag} / \mathrm{AgCl})$ was used as a reference electrode, and a platinum wire was used as the counter electrode. The Tafel extrapolation was used to obtain corrosion current $\left(i_{\text {corr }}\right)$ and the corrosion potential $\left(E_{\text {corr }}\right)$. The rate of corrosion was calculated from the following equation [16];

$$
C_{\text {rate }}=C \frac{M i_{\text {corr }}}{n \rho} .
$$

$C$ is a constant with a value of 3.27 for the corrosion rate $\left(C_{\text {rate }}\right)$ calculation in the unit of mmpy (mm per year) [17]. $M$ is the atomic weight $\left(\mathrm{g} \mathrm{mol}^{-1}\right), i_{\text {corr }}$ is the corrosion density $\left(\mathrm{A} \mathrm{cm}^{-2}\right), n$ is the number of electrons involved and was 3 in the present system, and $\rho$ is the density of the aluminum alloy with a value of $2.7 \mathrm{~g} \mathrm{~cm}^{-3}$.

The polyurethane/carbon/organoclay composites (a surface area of $2 \mathrm{~cm} \times 2 \mathrm{~cm}$ ) coated the aluminum alloy as a working electrode with a thickness of $0.35 \mathrm{~mm}$. The specimen was thoroughly immersed in $100 \mathrm{~mL}$ of $3.5 \% \mathrm{NaCl}$.

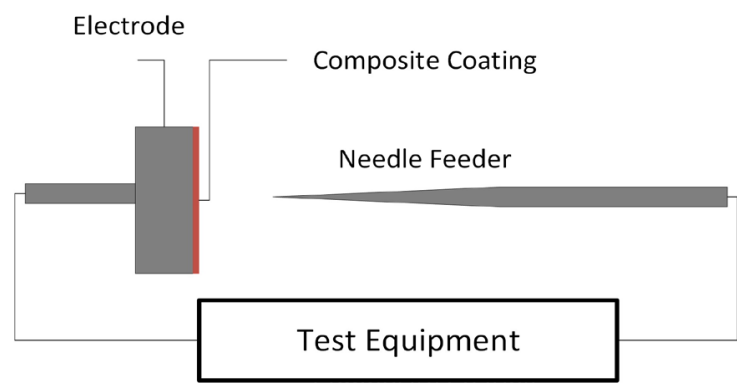

Figure 2: Schematic diagram for the partial discharge test. 
Partial discharge testing was used to measure partial discharge release from the surface of the coating. The partial discharge test circuit is depicted in Figure 2. The circuit consisted of an AC power supply. The partial discharge measurement was carried out using Omicron MPD 600, which is a partial discharge measurement system. The aluminum alloy plate coated with the coating material was mounted on the electrode side and confronted with a needle feed to provoke partial discharge. The distance between the aluminum alloy plate and the needle feeder was $10 \mathrm{~cm}$. The voltage was increased gradually from 0 to $15 \mathrm{kV}$.

Agilent HP 4284A was used to measure the capacitance as a function of the frequency with a range between $50 \mathrm{kHz}$ and $1 \mathrm{MHz}$. The composite was placed between two aluminum alloy plates and acted as a parallel capacitor. The relative permittivity was determined by dividing the material permittivity with the vacuum permittivity.

\section{RESULTS}

\section{A. Potentiodynamic polarization}

The 3.5-wt $\% \mathrm{NaCl}$ solution was used to test the corrosion properties of the samples. Chloride ions come from a group of strong acids that can damage the metal oxide layer. The P0, PCClay1, PCClay3, and PCClay coating materials were tested for their ability to slow down the corrosion process.

The result of this polarization method is illustrated as a curve between the potential and the current. The Tafel method was used to determine the corrosion rate based on the polarization curve versus $\log i$. Anodic and cathodic polarization produces a straight line with a particular slope. The intersection between anodic and cathodic polarization gives $E_{\text {corr }}$ and $i_{\text {corr. }}$ Figure 3 shows the Tafel polarization curves of the conductors without coatings (the aluminum alloy itself), a polyurethane coating ( $\mathrm{P} 0)$, and three polyurethane/carbon/organoclay coatings (PCClay1, PCClay3, and PCClay5). The potentiodynamic polarization data are presented in Table 2. A simultaneous addition of carbon and clay to polyurethane showed an improved corrosion re-

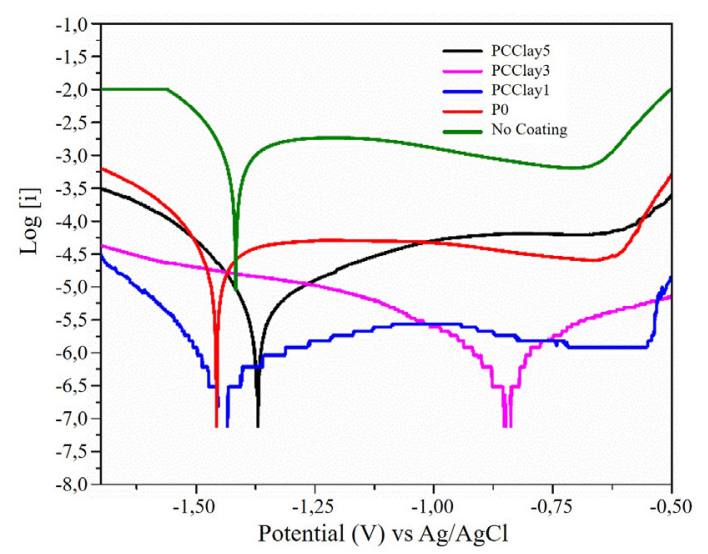

Figure 3: Tafel curves of the aluminum alloys coated with the PCClay composites.
Table 2: $i_{\text {corr }}$ and $E_{\text {corr }}$ of the aluminum alloys coated with the PCClay composites.

\begin{tabular}{lccc}
\hline Sample & $i_{\text {corr }}\left(\mathrm{A} \mathrm{cm}^{-2}\right)$ & $E_{\text {corr }}(\mathrm{V})^{a}$ & $C_{\text {rate }}(\mathrm{mmpy})$ \\
\hline No coating $^{b}$ & $8.27 \times 10^{-5}$ & -1.417 & $2.25 \times 10^{-1}$ \\
P0 & $2.06 \times 10^{-5}$ & -1.457 & $5.61 \times 10^{-2}$ \\
PCClay1 & $5.78 \times 10^{-7}$ & -1.435 & $1.57 \times 10^{-3}$ \\
PCClay3 & $6.21 \times 10^{-7}$ & -0.840 & $1.69 \times 10^{-3}$ \\
PCClay5 & $3.89 \times 10^{-6}$ & -1.371 & $1.06 \times 10^{-2}$ \\
\hline
\end{tabular}

${ }^{a}$ Potentials referenced to $\mathrm{Ag} / \mathrm{AgCl}$.

${ }^{b}$ The aluminum alloy without the coating.

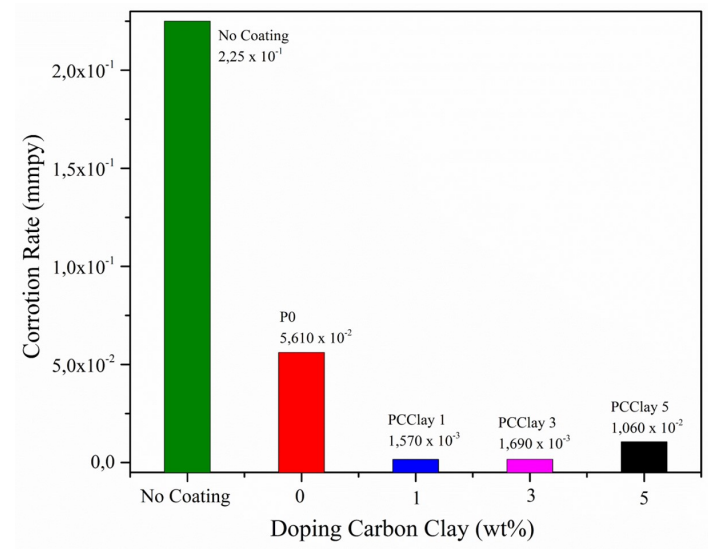

Figure 4: Corrosion rate of the aluminum alloys coated with the PCClay composites.

sistance compared to the one without the filler material.

Figure 3 and Table 2 show that adding 1\% carbon and 1\% clay to polyurethane succeeded in reducing $i_{\text {corr }}$ from $2.06 \times$ $10^{-5}$ to $5.78 \times 10^{-7} \mathrm{~A} \mathrm{~cm}^{-2}$ and $E_{\text {corr }}$ from -1.457 to -1.435 $\mathrm{V}$ so that it succeeded in reducing the corrosion rate from $5.61 \times 10^{-2}$ to $1.57 \times 10^{-3} \mathrm{mmpy}$. However, the addition of carbon and clay with the concentrations of $3 \mathrm{wt} \%$ each showed an increase in $i_{\text {corr }}$ and $E_{\text {corr }}$; an increase in the fillers from $1 \%$ to $3 \%$ enhanced $i_{\text {corr }}$ from $5.78 \times 10^{-7}$ to $6.21 \times$ $10^{-7} \mathrm{~A} \mathrm{~cm}^{-2}$. Likewise, when adding $5 \mathrm{wt} \%$ of the fillers, $i_{\text {corr }}$ increased to $3.89 \times 10^{-6} \mathrm{~A} \mathrm{~cm}^{-2}$.

$E_{\text {corr }}$ of the samples seems to shift to more cathodic when the filler content increases; however, $E_{\text {corr }}$ of PCClay3 seemed different from those of the other materials. Generally, $E_{\text {corr }}$ of materials shifts to more cathodic if the surface is not easily oxidized. It seems that the PCClay 3 composite covers the surface of the aluminum alloy with good adhesion between the composite and the aluminum alloy [12]. On the other hand, as the filler content increases from 3 to $5 \mathrm{wt} \%$, agglomeration and imperfection are more likely to occur. Imperfection can be a path to connect the surface of the composite to the surface of the aluminum alloy. This may be a reason why PCClay5 is less cathodic than PCClay3.

Figure 4 shows a decrease in the corrosion rate as the content of carbon/clay increases. The reduction in the corrosion rate from P0 to PCClay1, PCClay3, and PCClay5 was 


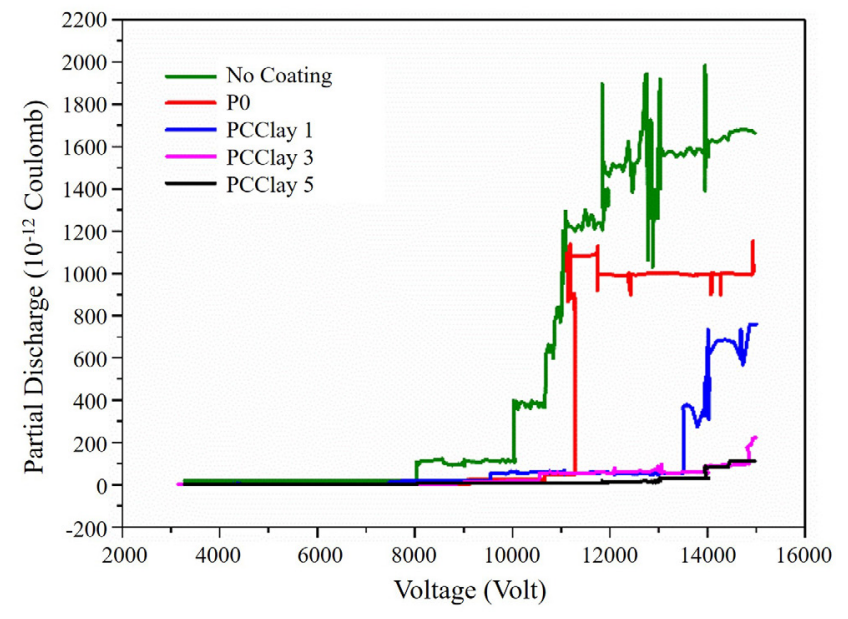

Figure 5: Partial discharge of the aluminum alloy coated with the PCClay composites.

$97.2 \%, 96.9 \%$, and $81.1 \%$ respectively. The test concluded that the polyurethane/carbon/organoclay coatings with 1, 3, and $5 \mathrm{wt} \%$ of the fillers on the aluminum alloy conductor are effective in reducing the corrosion rate compared to the one without the coating. An increase in the filler content also causes a decrease in the rate of corrosion.

\section{B. Partial discharge}

Figure 5 depicts curves of the partial discharge of the aluminum alloy conductors versus the voltage, and Table 3 presents the average partial discharge that arose at each voltage step to facilitate the analysis. All tested samples appear to have an increase in partial discharges with the voltage. Differences in partial discharge that occurred in each of the samples are recognized. It is evident that increasing the fillers had succeeded in reducing the partial discharge; for example, in the step voltage of $14-15 \mathrm{kV}$, the addition of the fillers with a concentration of $5 \mathrm{wt} \%$ reduced the partial discharge by almost $90 \%$ from $1012.2 \times 10^{-2}$ to $99.3 \times 10^{-12}$ C.

Table 3: Average partial discharge of the aluminum alloys coated with the PCClay composites for each step of the voltage.

\begin{tabular}{ccccc}
\hline \multirow{2}{*}{$\begin{array}{c}\text { Voltage } \\
(\mathrm{kV})\end{array}$} & \multicolumn{4}{c}{ Average Partial Discharge $\left(10^{-12} \mathrm{C}\right)$} \\
\cline { 2 - 5 } & P0 & PCClay1 & PCClay3 & PCClay5 \\
\hline 0 & 0 & 0 & 0 & 0 \\
$0-8$ & 2.6 & 2.4 & 1.3 & 1.1 \\
$8-9$ & 2.7 & 20.6 & 7.4 & 4.2 \\
$9-10$ & 22.6 & 27.6 & 18.2 & 7.2 \\
$10-11$ & 28.1 & 58.8 & 50.9 & 7.8 \\
$11-12$ & 961.0 & 56.8 & 56.1 & 10.1 \\
$12-13$ & 989.9 & 52.6 & 60.7 & 14.9 \\
$13-14$ & 994.8 & 317.4 & 66.4 & 44.8 \\
$14-15$ & 1012.17 & 627.1 & 127.9 & 99.3 \\
\hline
\end{tabular}

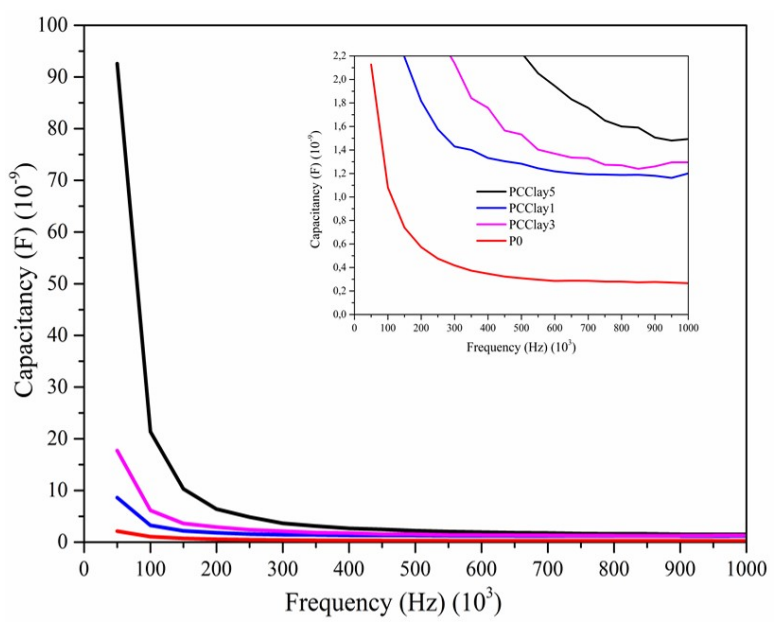

Figure 6: Capacitance of the PCClay composites as a function of the frequency. Inset shows the same date with a magnified scale in the vertical axis.

Table 3 shows an effectiveness of carbon/organoclay to reduce partial discharge by suppressing the possibility of corona. The test concluded that the use of the polyurethane/carbon/organoclay coatings with 1,3 , and $5 \mathrm{wt} \%$ fillers on the aluminum alloy conductor succeeded in reducing the partial discharge of the conductor compared with the one without a coating, and the increasing amount of the fillers also decreased the partial discharge.

\section{Capacitance}

Figures 6 presents results of the capacitance test, which was carried out by varying the frequency from 50 to 1000 $\mathrm{kHz}$. The carbon/clay filler with 1,3 , and $5 \mathrm{wt} \%$ in polyurethane increased the capacitance value. The values at the frequencies of $50,400,600,800$, and $1000 \mathrm{kHz}$ were listed in Table 4. At $50 \mathrm{kHz}$, there was an increase in the capacitance value for each filler addition; the value on the composite without filler $(\mathrm{P} 0)$ is $2.13 \times 10^{-9} \mathrm{~F}$, and those on the composite with the fillers (PCClay1, PCClay3, and PCClay5) increased to $8.62 \times 10^{-9}, 17.72 \times 10^{-9}$, and 92.59 $\times 10^{-9} \mathrm{~F}$, respectively. At $400 \mathrm{kHz}$, the difference in the capacitance depending on the filler amounts becomes smaller; the capacitance of P0 was $0.35 \times 10^{-9} \mathrm{~F}$, and those of PCClay1, PCClay3, and PCClay5 were $1.33 \times 10^{-9}, 1.76 \times$ $10^{-9}$, and $2.68 \times 10^{-9} \mathrm{~F}$, respectively. The same trend also

Table 4: Capacitance of the composites.

\begin{tabular}{ccccc}
\hline \multirow{2}{*}{$\begin{array}{c}\text { Frequency } \\
\left(10^{3} \mathrm{~Hz}\right)\end{array}$} & \multicolumn{4}{c}{ Capacitance $\left(10^{-9} \mathrm{~F}\right)$} \\
\cline { 2 - 5 } & P0 & PCClay1 & PCClay3 & PCClay5 \\
\hline 50 & 2.13 & 8.62 & 17.72 & 92.59 \\
400 & 0.35 & 1.33 & 1.76 & 2.68 \\
600 & 0.29 & 1.22 & 1.37 & 1.95 \\
800 & 0.28 & 1.19 & 1.27 & 1.60 \\
1000 & 0.27 & 1.21 & 1.29 & 1.49 \\
\hline
\end{tabular}




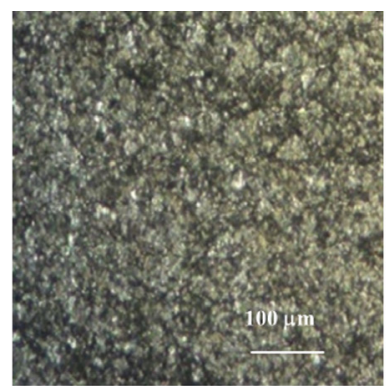

(a) P0

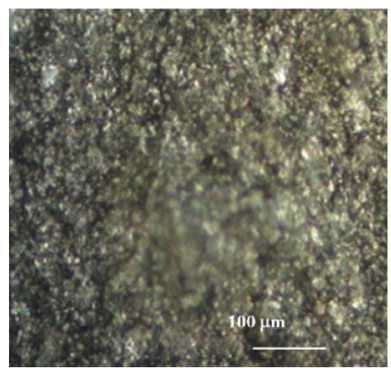

(c) PCClay3

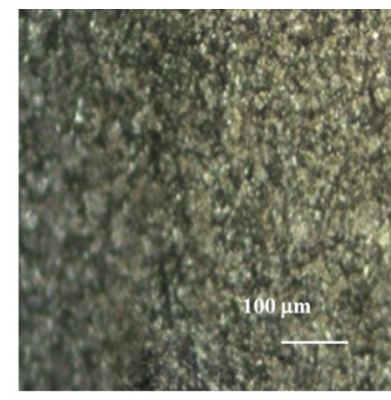

(b) PCClay 1

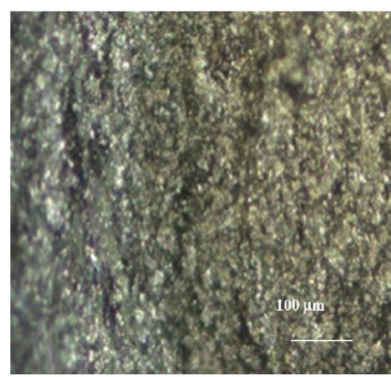

(d) PCClay5
Figure 7: Optical observation of the composite surfaces.

occurred at 600,800 , and $1000 \mathrm{kHz}$.

The test results showed that the carbon/organoclay filler material in polyurethane was able to increase the capacitance value.

\section{Optical microscope observation}

Observation of the surface morphology of the samples was conducted by using an optical microscope. It was intended to see the differences in morphology of the sample surfaces due to the different filler content. Figure 7 shows that morphology of the samples is more or less different. Such difference might come from the difference in the amount of the filler content, because the mixing time was constant but the filler content varied. This might cause inhomogeneity in the distribution of the fillers in polyurethane.

Mixing of carbon and organoclay with polyurethane was carried out using a magnetic stirrer. The mixing time must be sufficient to homogenize the distribution of the filler particles in polyurethane. However, if the mixing time is not sufficient, the distribution of the particles may not be homogenous. Therefore, agglomeration of the particles may occur in polyurethane.

\section{DISCUSSION}

The results of the potentiodynamic polarization test shows that the corrosion rate of the aluminum alloy coated with PCClay is lower than that of the aluminum alloy without the coating. Even when the surface of the aluminum alloy is covered with the composite, the water vapor or other substances in a very small portion can permeate the composite to reach the surface of the aluminum alloy [12]. The vapor acts as an electrolyte, which electrically connects the aluminum surface to the surface of the composite or to the outer part of the samples. With increasing the filler content in the composite, the corrosion rate decreases.

The corrosion process depends on the electrical resistance of the materials that cover the surface of the aluminum alloy. Polyurethane is a dielectric, but the vapor penetrates in a limited portion [12]. This vapor can act as a conductor to transport electrons from the surface of the coating to the surface of the aluminum alloy. Figure 6 shows that the capacitance increases as the amount of the filler increases. Since the capacitance depends on the dielectric constant, the dielectric constant increases as the filler content increases. The small corrosion rate may be due to the dielectric properties of polyurethane and organoclay. The addition of carbon may lead to a small increase in the corrosion rate because carbon is a conductor. The organoclay contributes more on reducing the corrosion rate.

Inorganic organoclay consisting of layered silicates have been used in the polymer industry. Layered silicates clay provides barrier properties and high impedance for the coating systems $[18,19]$. In other words, increasing the organoclay content in polyurethane leads to an improvement in the corrosion protection as shown in Figure 3 and Table 2.

Partial discharge can be defined as an electrical discharge that may occur across a localized area of the insulation between two conducting electrodes without completely bridging the gap. When the strength of the local electrical field is sufficient to breakdown the portion of the dielectric material, partial discharge occurs. Imperfections, discontinuities, voids, or cavities in the insulating system or delamination may cause partial discharge. Figure 5 shows that partial discharge decreases as the filler content increases. Carbon used in this research was a solid crystalline and was conductive while the organoclay was a solid amorphous and was less conductive or insulating. Polyurethane is an organic material and is more prone to deterioration than carbon and organoclay [12].

Charge polarization induced by the electric field may occur in the materials. If the materials are not strong enough to withstand the electric field, they may break down and be deteriorated. The path of the charge in the material is the region where the local electrical resistance is the lowest. Some portion of the materials is burnt after partial discharge due to the heat developed.

Figure 5 shows the different patterns of the partial discharge of each sample. The P0 partial discharge pattern seems stepwise and then constant. The imperfection in polyurethane was dominated by one type of imperfections, namely a void. Increasing the content of the filler suppressed the partial discharge and increased the voltage where the partial discharge started to occur. Comparing the properties between carbon and the organoclay, it seems that the organoclay fillers dominated the suppression of the partial discharge compared to carbon.

Discharge generally appears as pulses with a typical dura- 
tion of less than $1 \mu \mathrm{s}$. While very short in duration, the released energy can interact with the surrounding dielectric material, resulting in further insulation degradation and eventually, if left unchecked, the insulation will fail.

In line with the partial discharge properties, dielectric properties obtained from measuring the capacitance of the materials is also important. The capacitance is a function of the geometry and the permittivity of the dielectric material inserted between the plates of the capacitor. For many dielectric materials, the permittivity does not depend on the potential difference between the conductors and the total charge on them. When a dielectric material is placed in an electric field, electric charges do not flow through the material; however, polarization occurs. The positive charge is displaced in the direction of the field and the negative charge shifts in the direction opposite to the field. A leakage current may occur if a material does not withstand the electric potential difference. Before the leakage, partial discharge occurs first. Figure 8 shows that the capacitance of the samples increases as the filler content increase. If the capacitance increases, the dielectric constant of the composite increases so that the composite withstands higher voltages. This should result in suppression of partial discharge. The organoclay contributes more than carbon on the dielectric properties and partial discharge.

Figure 6 shows the behavior of the capacitance as a function of the frequency. The capacitance is high at low frequencies, but it is low at high frequencies. It seems that, at the high frequencies, the charge carriers and the dipole movements can freely move inside the material during the test and follow the alternation of the electromagnetic field. Conversely, at the low frequencies, the charge carriers and the dipole cannot easily follow the variations of the applied electric field with increasing in the capacitance. The high values in the low-frequency range can exist in one or more of the following processes: (i) electrode polarization, (ii) interfacial polarization, and (iii) conductivity phenomena. Electrode polarization is usually a parasitic effect due to the electrode-sample contact. Interfacial polarization or Maxwell-Wagner-Sillars effect might occur in systems exhibiting

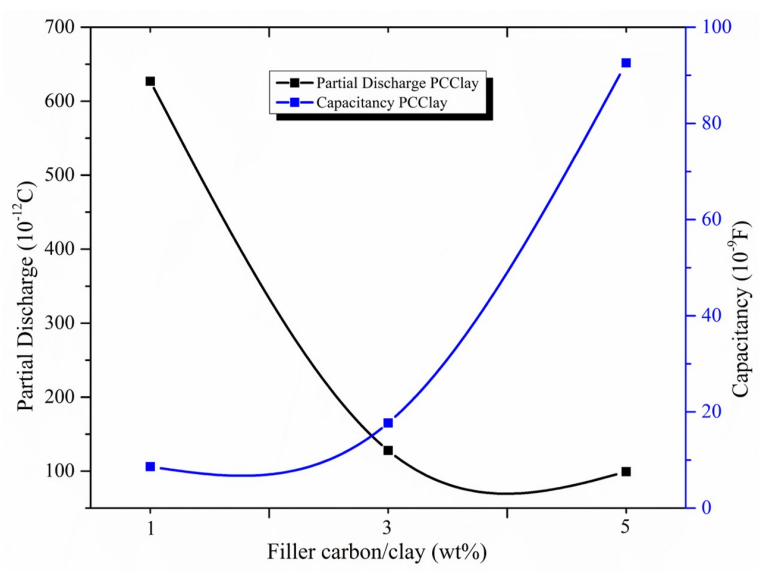

Figure 8: Partial discharge and capacitance as a function of the filler content at $50 \mathrm{kHz}$ frequency. heterogeneity. This might be the case in polymer matrix-inorganic filler composites and also due to the accumulation of mobile charges at the interface of their fillers [20].

The relationship between partial discharge, the capacitance, and the filler content is illustrated in Figure 8. Observations of these correlations were taken at a frequency of 50 $\mathrm{kHz}$. As the fillers increases, the capacitance increases, and partial discharge decreases. This suggests that partial discharge of materials can be suppressed as the capacitance of the materials is enhanced.

\section{CONCLUSION}

Polyurethane/carbon/organoclay (PCClay) composite materials were coated onto the aluminum alloy conductors. PCClay could reduce the corrosion rate and suppress partial discharge. The capacitance and partial discharge values depend on the amount and type or properties of the filler materials. PCClay is possible to be used as a coating material for the aluminum alloy conductors in high voltage applications.

\section{Acknowledgments}

The authors send gratitude for the financial support from the Ministry of Research, Technology, and Higher Education of Indonesia (RISTEK-DIKTI), under the grant of Hibah Penelitian Dasar Unggulan Perguruan Tinggi No. NKB-1588/UN2.R3.1/HKP.05.00/ 2019.

\section{References}

[1] N. Murray, F. Besnard, D. B. McGuire, and K. J. Scissum, 2016 IEEE/PES Transmission and Distribution Conference and Exposition (T\&D) (Dallas, 2016) pp. 1-5.

[2] Y. Yi, C. Zhang, and L. Wang, IET Sci. Meas. Technol. 10, 557 (2016).

[3] X. Z. Zhao, Z. X. Yang, M. Y. Zhao, L. Wang, and Z. C. Fu, Adv. Mater. Res. 1092-1093, 233 (2015).

[4] R. Zhang, N. Zheng, G. Guo, X. Fu, and Y. Jiang, J. Electrostat. 77, 1 (2015).

[5] N. A. Jaffrey and S. Hettiwatte, 2014 Australasian Universities Power Engineering Conference (AUPEC) (Perth, Western Australia, 2014) pp. 1-6.

[6] M. R. Rahimi, R. Javadinezhad, and M. Vakilian, 2015 IEEE 11 th International Conference on the Properties and Applications of Dielectric Materials (ICPADM) (Sydney, 2015) pp. 260-263.

[7] B. Pilch-Pitera, Prog. Org. Coat. 77, 1653 (2014).

[8] B. Adak, B. S. Butola, and M. Joshi, Appl. Clay Sci. 161, 343 (2018).

[9] X. Cao, L. James Lee, T. Widya, and C. Macosko, Polymer 46, 775 (2005).

[10] L. Song, Y. Hu, Y. Tang, R. Zhang, Z. Chen, and W. Fan, Polym. Degrad. Stab. 87, 111 (2005).

[11] E. Ciecierska, M. Jurczyk-Kowalska, P. Bazarnik, M. Gloc, M. Kulesza, M. Kowalski, S. Krauze, and M. Lewandowska, Compos. Struct. 140, 67 (2016).

[12] O. Kurniawan and B. Soegijono, e-J. Surf. Sci. Nanotechnol. 18, 62 (2020).

[13] T. Tanaka, Y. Ohki, M. Ochi, M. Harada, and T. Imai, IEEE Trans. Dielectr. Electr. Insul. 15, 81 (2008). 
[14] G. Iyer, R. S. Gorur, and A. Krivda, IEEE Trans. Dielectr. Electr. Insul. 19, 118 (2012).

[15] X. Huang, Y. Li, F. Liu, P. Jiang, T. Iizuka, K. Tatsumi, and T. Tanaka, IEEE Trans. Dielectr. Electr. Insul. 21, 1516 (2014).

[16] O. S. I. Fayomi, I. G. Akande, A. P. I. Popoola, and H. Molifi, J. Mater. Res. Technol. 8, 3088 (2019).

[17] Z. Ahmad, Principles of Corrosion Engineering and Corrosion Control (Butterworth-Heinemann, 2006).

[18] S. Sinha Ray and M. Okamoto, Prog. Polym. Sci. 28, 1539 (2003).

[19] A. Rehab and N. Salahuddin, Mater. Sci. Eng. A 399, 368 (2005).

[20] K. Gatos, J. Martínez-Alcázar, G. Psarras, R. Thomann, and J. Karger-Kocsis, Compos. Sci. Technol. 67, 157 (2007).

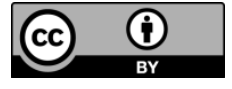

All articles published on e-J. Surf. Sci. Nanotechnol. are licensed under the Creative Commons Attribution 4.0 International (CC BY 4.0). You are free to copy and redistribute articles in any medium or format and also free to remix, transform, and build upon articles for any purpose (including a commercial use) as long as you give appropriate credit to the original source and provide a link to the Creative Commons (CC) license. If you modify the material, you must indicate changes in a proper way.

Published by The Japan Society of Vacuum and Surface Science 